\title{
Virtual Reality Technology and Museum Exhibit
}

\author{
Michitaka Hirose
}

\begin{abstract}
More than 15 years have passed since the word "virtual reality" became popular in our society. Now VR technology is at the stage where realistic application should be discussed. For example, it is said that museums are now a good application field of VR technology. In this paper, recent VR technologies which can be utilized for museum exhibits are introduced. The topics include sophisticated image environments such as IPT (immersive projection technology), image-based world generation methodology, and "real world VR" supported by wearable computers.
\end{abstract}

Index Terms - Virtual reality, Three-dimensional displays, User Interfaces, Rendering (computer graphics)

\section{INTRODUCTION}

More than 15 years have passed since the word "virtual reality (VR)" became popular in our society. At the beginning, this technology attracted people's interests just because it provided novel experiences such as stepping into a computer-generated artificial 3D world, grasping virtual objects or other experiences which were impossible in the real world. However, nowadays, we require more serious content or application for this technology. One of the most important roles of this technology is to visualize various objects that are difficult to understand intuitively. In this context, VR technology should be able to provide various possibilities for conventional museum exhibits.

\section{VR THEATER FOR MUSEUM}

\section{A. IPT (Immersive Projection Technology)}

In 1992, CAVE, the first IPT was invented at the University of Illinois as the most sophisticated VR system at that time. The virtual world generated by IPT is of high quality and is also very stable because the IPT consists of already commercialized components such as stereo projectors, high end graphics workstations. Fig. 1 shows "CABIN", which was constructed at IML (Intelligent Modeling Laboratory) at the University of Tokyo in 1997. CABIN, which has 5 screens, can provide a

Manuscript Received on August 20, 2006.

Michitaka Hirose is with Graduate School of Information Science and Technology, The University of Tokyo, 113-8656 7-3-1 Hongo, Bunkyo-ku, Tokyo, Japan (corresponding author to provide phone: +81-3-5841-6367; fax: +81-3-5800-6977; e-mail: hirose@ cyber.rcast.u-tokyo.ac.jp). high-resolution image with very wide field of view of more than 270 degrees [1].

This high-quality environment enables us to apply VR technology to more serious applications such as museum exhibits. In fact, recently, the use of VR technology in museum exhibits has become one of its most important application fields.

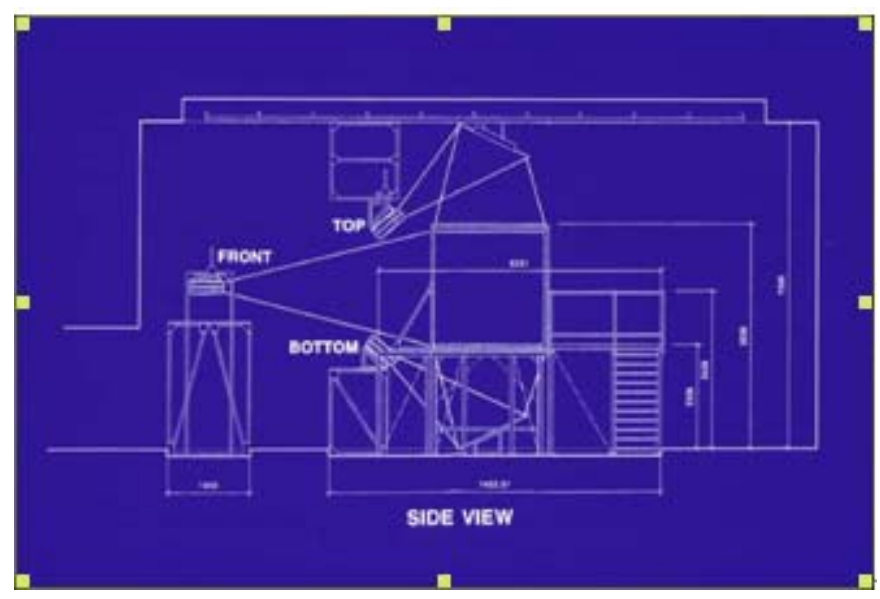

Fig. 1. CABIN was constructed in IML (Intelligent Modeling Laboratory) at the University of Tokyo in 1997.

\section{B. VR theater for Mayan Exhibition}

From March 18 through May 18, 2003, the Mayan Civilization exhibition was held at the National Science Museum in Ueno and a large-scale VR theater was constructed there in collaboration with our laboratory. The theater was an important element of the exhibition. Among the 200,000 visitors, 120,000 visited the theater and enjoyed the VR images. Reconstructed Copan ruins were projected onto a large screen, and visitors enjoyed their virtual stroll of the ruins, which actually existed on the other side of the earth. Conventionally, in most ancient civilization exhibitions, excavated articles are displayed and simply explained. However, displays and explanations are not sufficient for most museum visitors to understand the location of the excavation, the extent of the ruins, and the lifestyle of the people at that time.

The theater included a huge curved screen $(4 \mathrm{~m} \times 14 \mathrm{~m})$ onto which three Hi-Vision equivalent images were projected (Fig. 2). A large-capacity graphic workstation (Onyx, SGI) was utilized for image generation. One of the reasons why the curved screen was used was that CABIN-type-IPT is not designed for a large audience.

Since the significant point of using VR technology in a museum is its interactivity, we have spent much effort on 


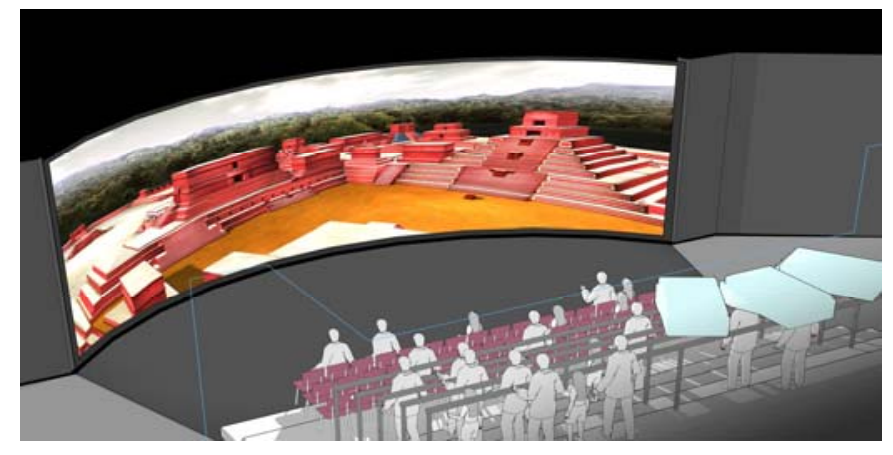

Fig. 2. Virtual Reality theater for Mayan Civilization exhibit held at the National Science Museum. See Color Plate 12

developing interactivity for use in a large theater. During the virtual guided tour in the VR theater, the actors operated a game-pad-type controller and gave commentary in accordance with the story written for their roles. When we think of a VR theater, we tend to consider a direct interaction between the audience and VR images. However, in this exhibition, the actors used the interactivity feature of images to represent the interaction between the VR images and the audience. This manner distinguished the VR image contents from regular game contents. I believe that the effectiveness of story-telling-style interactivity, which is not the same as that of games, has been well validated by this exhibit.

Two PCs were installed immediately outside the VR theater. By using the PC controllers, visitors could move freely around the VR world and look into places. When the visitor stopped operating the controller, the PC reverted to the view angle of the guide. That is, the relationship of the visitor with the theater and the PC varied; at one time, the visitors received guidance from the theater and at another, the visitors interacted on their own accord. Various ideas are being tested regarding the rules of the distribution of images using digital networks; guidance using the mildly restricted concept presented here is very promising [3].

\section{Virtual Mayan Ruins}

As content for the VR theater, a Mayan acropolis with an

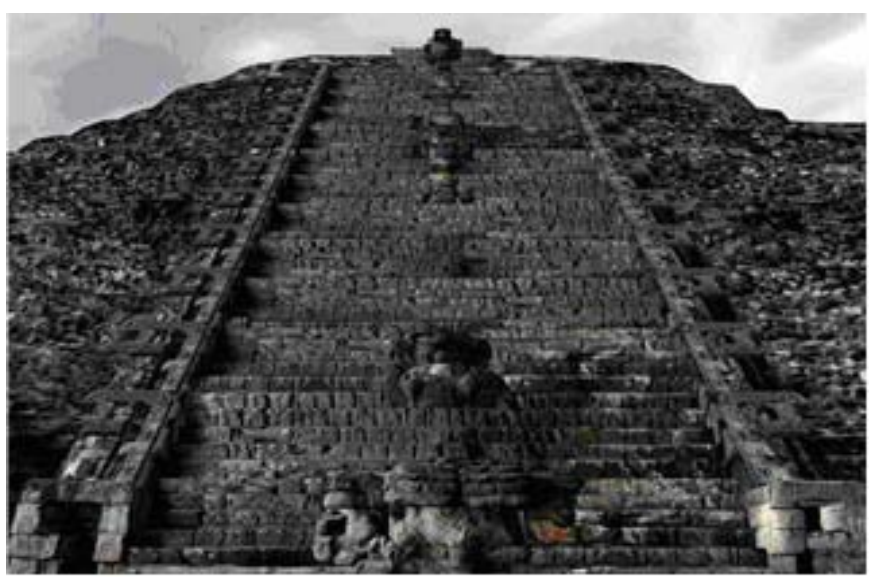

Fig. 3. Virtually synthesized No. 16 shrines at Copan ruins. See Color Plate 13 area of approximately $350 \mathrm{~m} \times 650 \mathrm{~m}$ was reconstructed as a three-dimensional (3D) world of images using computer graphics (CG). For texture mapping, 4,000 photos were used at multiple resolutions for the effective representation of the images of many tombstones existing in the ruins and of the trees present nearby.

Fig. 3 shows a pyramidal structure called the No. 16 shrines. It is amazing that this high-quality image can be experienced in

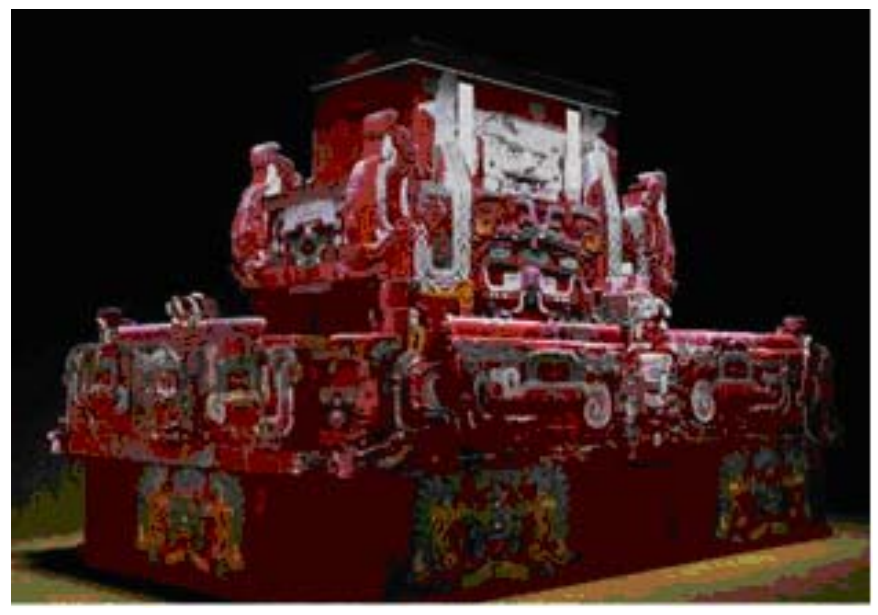

Fig. 4. Virtually synthesized Rosalia shrine at Copan ruins. See Color Plate 14

an interactive environment. It is said that many Mayan shrines were constructed on top of old buried shrines. Fig. 4 shows one such case; we can see the inner structure of the ruins. The Rosalia shrine is present underneath the newer structure that is shown in Fig. 3. In reality, it is very difficult to observe the entire image of buried shrines.

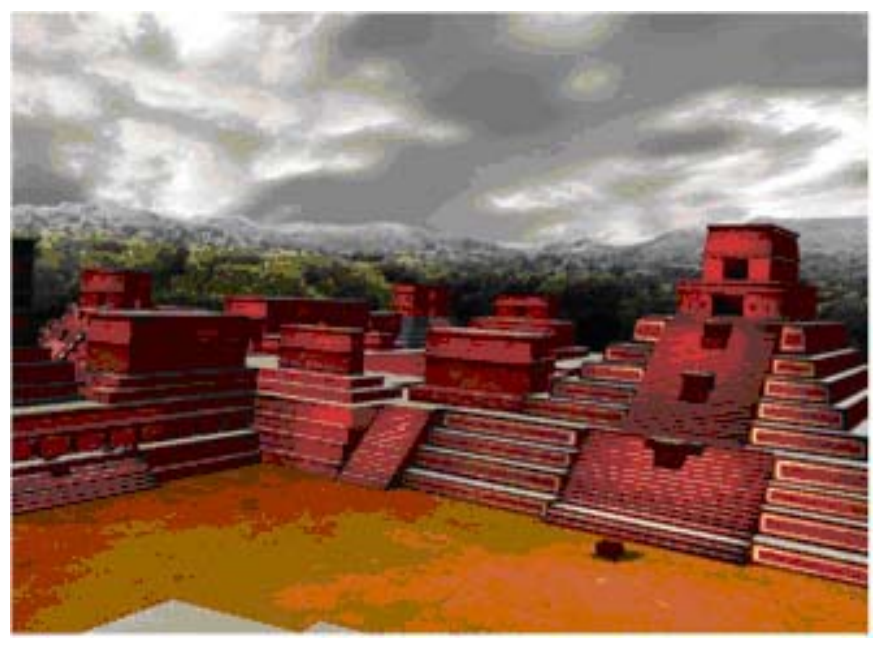

Fig. 5. Virtually synthesized Copan acropolis 1,200 years ago. See Color Plate 15

Fig.5 shows the ruins 1,200 years ago with colors reproduced on the basis of the investigation of pigments found on the ruins. Excavated artifacts were reconstructed, using computers, to appear in their functional form. This reproduction has been realized as a result of the full utilization of the simulation capabilities of computers. Very accurate 
The International Journal of Virtual Reality, 2006, 5(2):31-36

archeological discussion has become possible by the combination of simulation techniques and inference based on excavated artifacts.

\section{GENERATING 3D VR WORLD FROM DIGITAL PHOTOGRAPHS}

\section{A. Augmented Virtuality}

Mixed Reality (MR) technology is also an important technology that is closely related to VR technology. MR technology consists of AR (augmented reality) where a virtual world is superimposed onto the real world and AV (augmented virtuality) where real world information is imported into the virtual world.

AV technology will contribute to improving the cost efficiency of generating a photorealistic virtual world. For example, a large amount of manpower was needed to generate the Mayan ruins described above, which was made using 3D geometrical models and texture the mapping method. If we can use sophisticated IBR (image-based rendering) technology, by which 3D virtual space can be generated from 2D real photographic images, the required manpower will be greatly reduced.

The lower image of Fig. 6 is the depth map extracted from

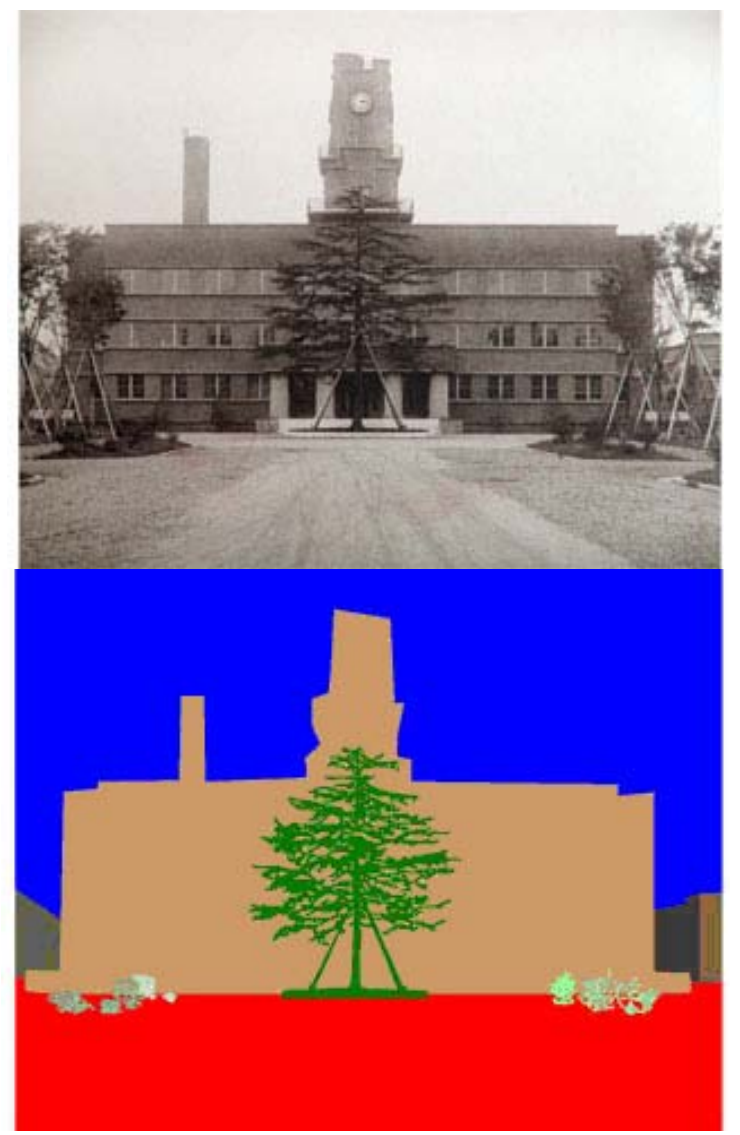

Fig. 6. Depth information can be estimated from 2D photos under several assumptions. the upper image, which is merely a 2D photograph under several assumptions such as "the ground is a flat surface" and "the walls of buildings are vertical to the ground." By using depth information, we should be able to estimate the 3D shape from the 2D image easily. This kind of technology is called "photo-pop-up".

\section{B. From 2D Images to 3D World}

The area where free walk-through is supported by this pseudo-3D model is very narrow. In other words, the 3D model is not 'global'. Therefore, we must connect each local 3D model into a global 3D model which supports a wider walk-through area.

Currently, by using the above-described methodology, we are planning to reconstruct the exhibit space of the old railway museum that was closed on May 24 $4^{\text {th }}$, 2006 for reconstruction. More than 35,000 digital photographs have already been taken. Fig. 8 shows the virtual walk-through synthesized from the images shown in Fig. 7. If you look carefully at the images, several double-image artifacts caused by registration error or camera parameter error can be observed.

If this technology is combined with wearable computer

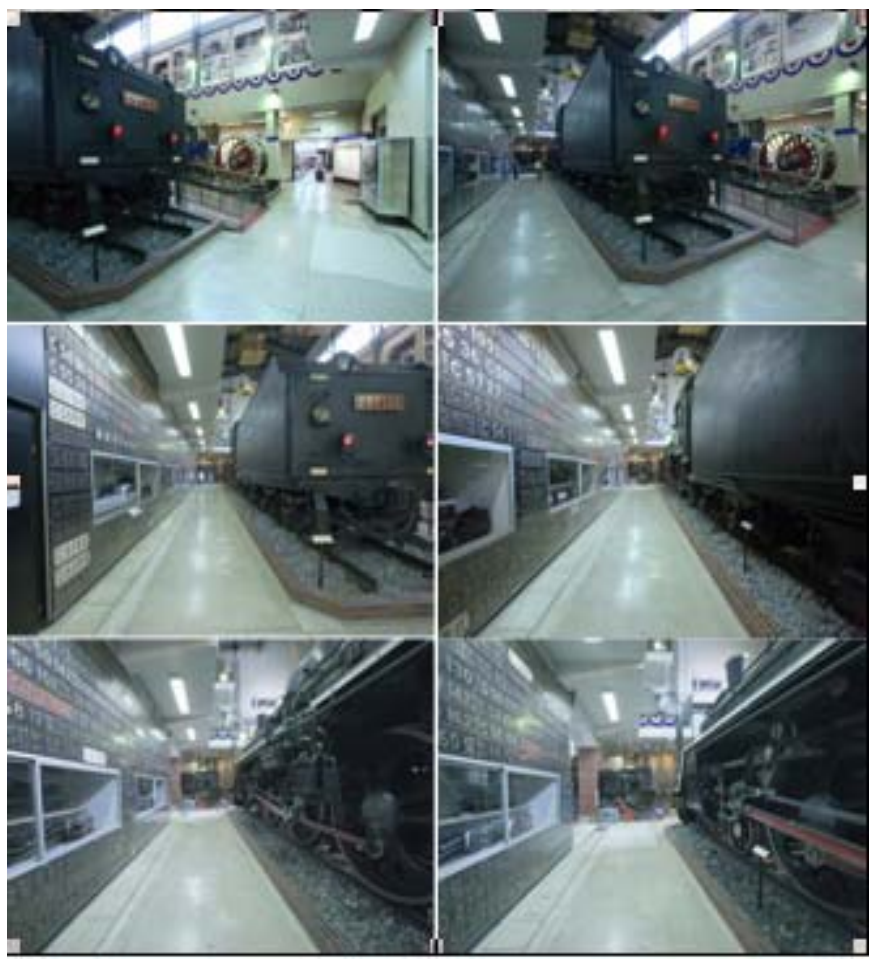

Fig. 7. Six example images out of 35,000 captured by digital camera. See Color Plate 16

technology, as shown in Fig. 9, a huge number of images can be gathered as a personal experience record. Integrated images from the past will provide us with an opportunity to experience the past, leading to the possibility of a "virtual time machine". 

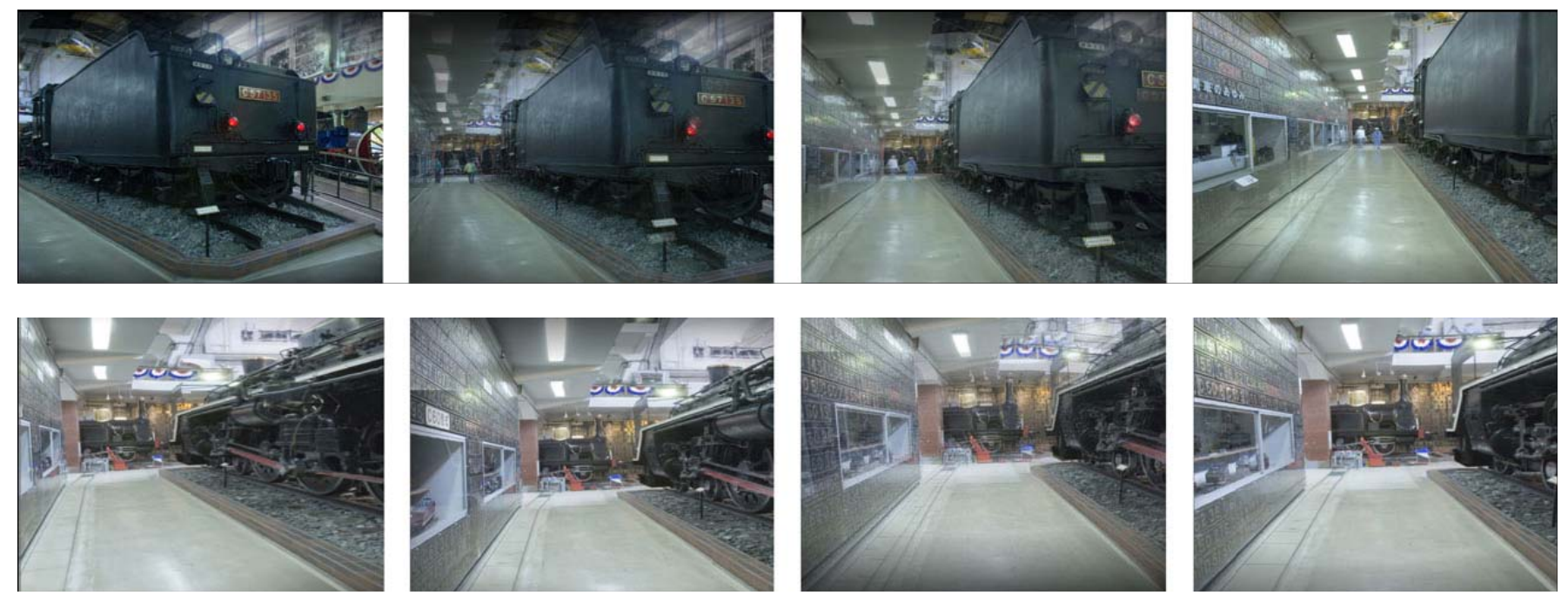

Fig. 8. Three-dimensional walk-through environment is synthesized from photo-pop-ups constructed from six images shown in Fig. 7. See Color Plate 17
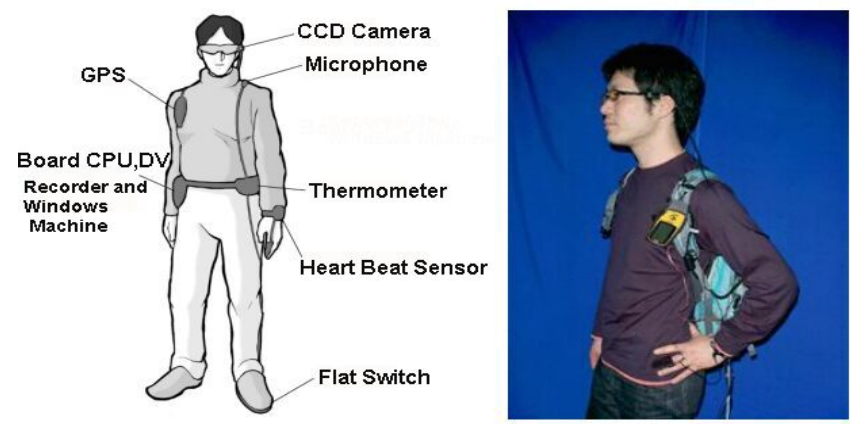

Fig. 9. Wearable computer for recording experience.

Since wide areas such as city landscapes can also be easily captured into computers by this methodology, we should be able to construct a "Museum of Cities". The concept of the Museum of Cities is very interesting because each exhibit, a city landscape, will be much larger than a museum building, and thus, this museum is possible only by using digital technology (Fig.10) [2].

\section{REAL-WORLD VIRTUAL REALITY}

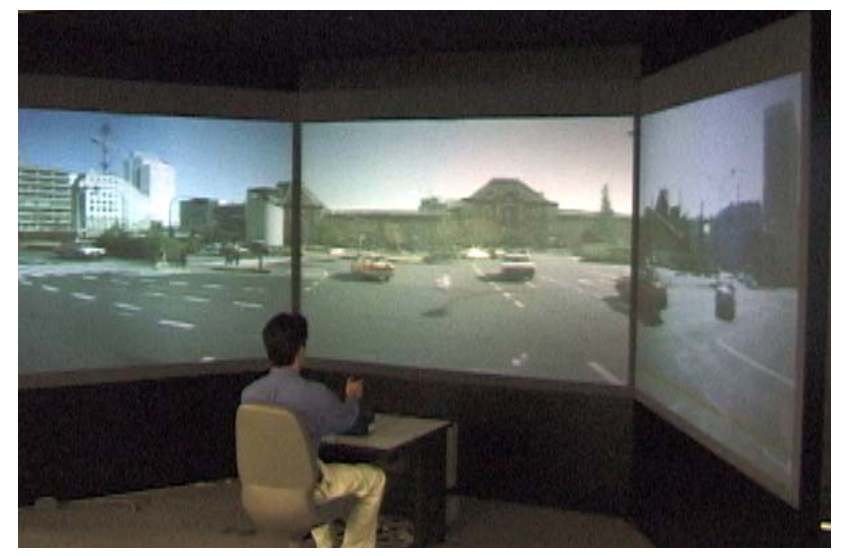

Fig. 10. Museum of Cities. See Color Plate 18

\section{A. Field Museum}

AR technology has the capability to extend the virtual world to the real world. By using wearable computers, we can see a virtual world superimposed on the real world. Fig. 11 shows a wearable computer prototype designed for a "field pavilion" at World Expo 2005. The field pavilion is a virtual pavilion that is intended to provide various exhibits in an outdoor environment by using wearable computers equipped with see-through HMD and GPS. The concept of the field pavilion, which has no

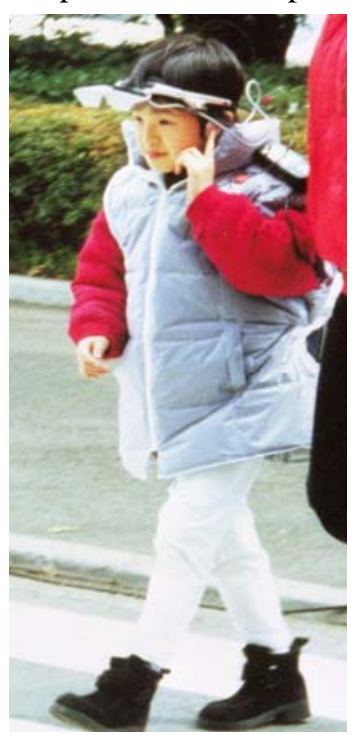

Fig. 11. Wearable computers designed for field pavilion at Expo 2005.

physical construction, is fascinating because one of the important themes of Expo 2005 was "harmonization between artificial and natural environments" [4].

In reality, at Expo 2005, the idea of the field exhibition was realized merely as a guiding system using a cellular phone system. Nonetheless, experiments to verifying the concept of the field exhibition have been carried out on various occasions as a new framework for displays in exhibitions. 
The International Journal of Virtual Reality, 2006, 5(2):31-36

\section{B. Ubiquitous Gaming}

In addition to Expo 2005, another example can be introduced: "ubiquitous gaming" demonstrated during the TV Games and Digital Science exhibition held at the National

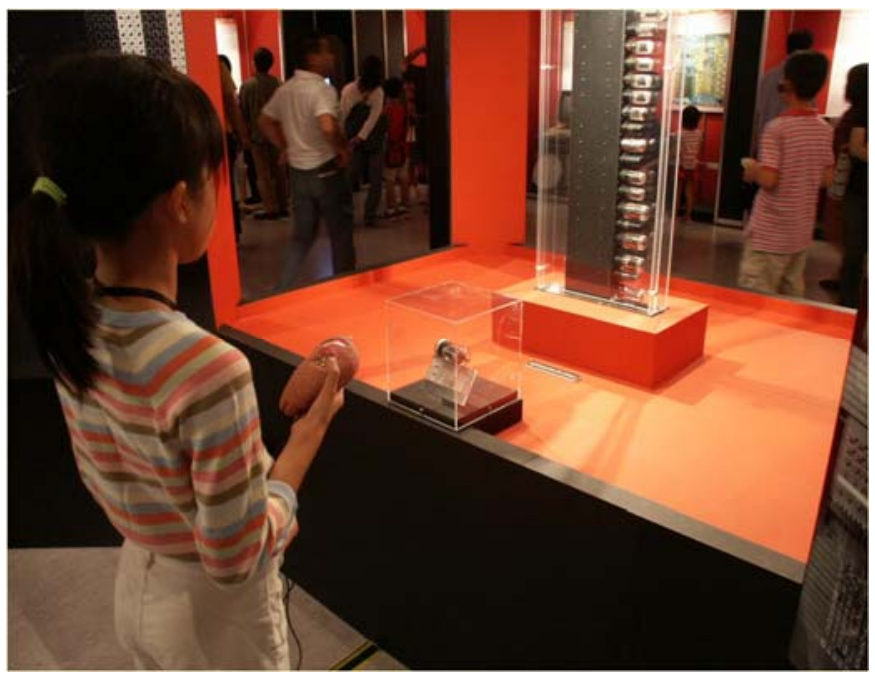

Fig. 12. Ubiquitous gaming was demonstrated at the National Science Museum. See Color Plate 19
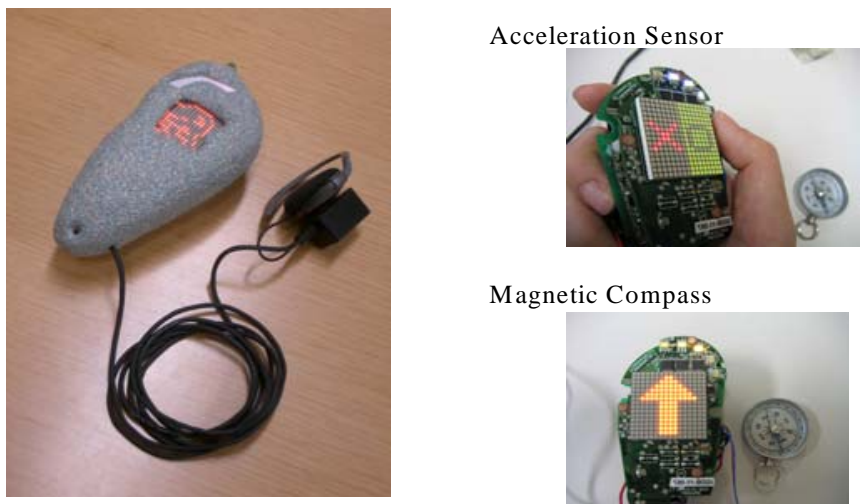

Magnetic Compass

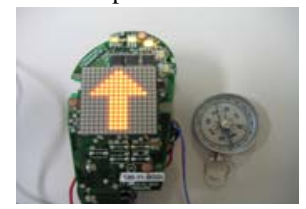

Fig. 13. Wallstones function as mobile interfaces between real and virtual worlds.

Science Museum from 17 July to 11 October 2004 (Fig. 12). Ubiquitous gaming is an activity in which visitors can enjoy their time while walking around a real space, for example, a museum. The participants in the game use small terminals called "wallstones", as shown in Fig. 13. Each terminal is equipped with input-output interfaces such as a 16x16-dot LED matrix, an audio output via an earphone, a vibration output, an acceleration sensor and an azimuth sensor.

The wallstone provides a novel interface between the computer and user. When visitors stand in front of an exhibit, they can hear the voice of a game character through the earphone and its image also appears on the LED display of the wallstone. As another function, numerical values can be input to the terminal by controlling the number of swings of the terminal, which is incorporated with an acceleration sensor [5].

\section{Wide-Range Positioning System}

One essential technology for implementing ubiquitous gaming is a positioning system with a large work range. As shown in Fig. 14, in order to support user location sensing, we installed 400 infrared transmitters, arranged in the form of a matrix, in the ceiling of an exhibition hall of approximately 500 $\mathrm{m}^{2}$. A positioning accuracy of $60 \mathrm{~cm}$ was achieved.

We are still working on other positioning systems because the IR system requires very labor-intensive installation. We believe that the recent CV (computer vision) technology has

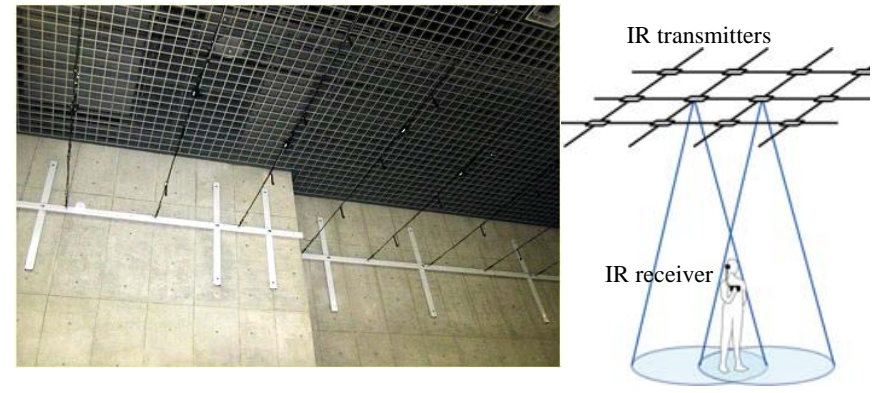

Fig. 14. More than 400 IR transmitters are used for position sensing.

high potential for application to this purpose. Fig. 15 shows a carpet or wallpaper whose pattern includes positioning information. By capturing this encrypted pattern, an intelligent small camera can calculate its own 3D position. The installation cost of this system is expected to be very low because this system requires no devices to be distributed in the installation cost of this system is expected to be very low because this

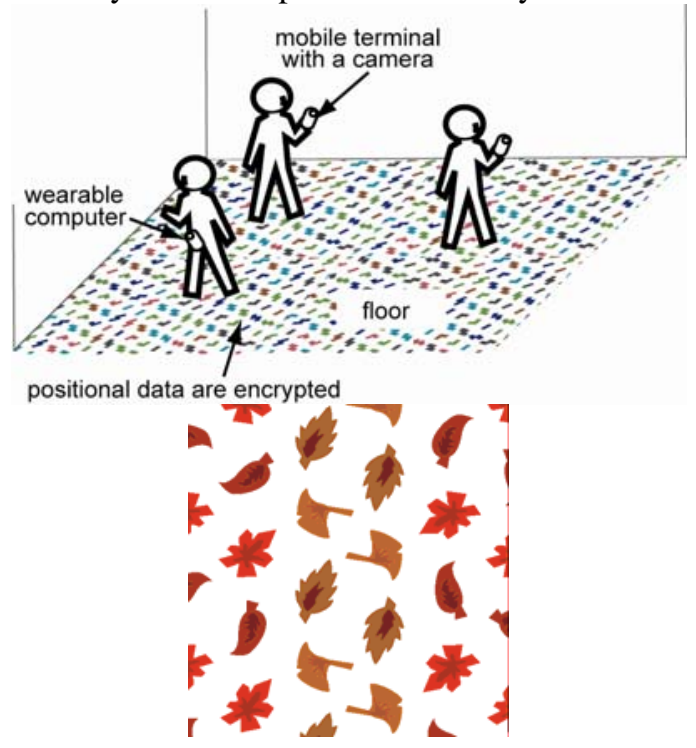

Fig. 15. Special carpet in which position code is encrypted.

system requires no devices to be distributed in the environment.

\section{CONCLUSION}

VR technology already has the potential for several serious applications. VR technology confined in laboratories as 
experimental equipment is being adopted in various fields such as museum exhibits. The quality of each component technology has been improved enormously. Novel technologies such as GPS, RFID tags, and mobile phones most of which were not available several years ago are now widely commercialized. In addition, VR hardware has become 10 to 100 times lower in cost than 10 years ago. Museum exhibits, where high-quality novel image technology is required, will be one of the most promising applications of VR technology.

\section{REFERENCES}

[1] M.Hirose. CABIN-A MultiScreen Display for Computer Experiments, Proc. 2rd Interna-tional Conf. On Virtual Systems and Multimedia (VSM M’97),pp78-83,1997

[2] M.Hirose, S.Watanabe. Generation of Wide-Range Virtual Spaces Using Photo-graphic Images, Proc. 4th IEEE VR Annual Conf. (VRA -IS'98), pp234-241,1998

[3] T. Tanikawa, M. Ando, Y. Wang, K.Yoshida, J.Yamashita, H.Kuzuoka, M.Hirose. A Case Study of Museum Exhibition -Historical Learning in Copan Ruins of Mayan Civiliza-tion- . Proc. IEEE Virtual Reality Conf. , pp.257-258, 2004

[4] A. Hiyama, et al. Development and Demonstration of Wearable Computer Based Interactive Nomadic Gallery, Proc. 6th IEEE Intl. Symp. On Wear -able computers (ISWC2002), pp.129-130,2002

[5] Atsushi Hiyama, Jun Yamashita, Yuichi Nishimura, Teiichi Nishioka, Koichi Hirota, Hideaki Kuzuoka and Michitaka Hirose. A Real World Role-Playing Game as an Application of the Guide System in a Museum. The 14th International Conference on Artificial Reality and Telexistence, pp.29-34, 2004

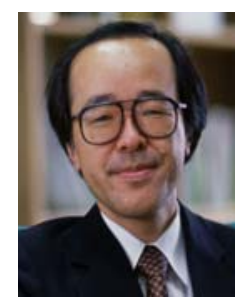

Michitaka Hirose was born in 1954 in Japan. He received BE in Mechanical Engineering, ME and Ph.D. degrees in Mechano-infor -matics from the University of Tokyo in 1977, 1979 and 1982 respectively.

Currently, he is a professor at Graduate School of Information Science and Technology, the University of Tokyo. His research interests include human interface, interactive computer graphics, wearable computer and virtual reality. He was a project leader of Multimedia Virtual Laboratory project and Scalable VR Contents project sponsored by ministry of general affairs.

Prof. Hirose is a member of the ACM, JSME(Japanese Society for Mechanical Engineers) and VRSJ(Virtual Reality Society of Japan). 